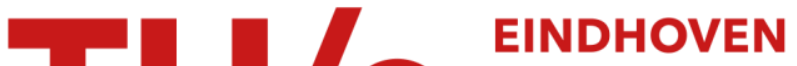 UNIVERSITY OF TECHNOLOGY
}

\section{On free-space antenna reflection phase measurements in a reverberation chamber}

Citation for published version (APA):

Bronckers, L. A., Roc'h, A., \& Smolders, A. B. (2019). On free-space antenna reflection phase measurements in a reverberation chamber. In 2018 IEEE International Symposium on Antennas and Propagation \& USNC/URSI National Radio Science Meeting (pp. 7-8). [8602581] Institute of Electrical and Electronics Engineers.

https://doi.org/10.1109/USNC-URSI.2018.8602581

DOI:

10.1109/USNC-URSI.2018.8602581

Document status and date:

Published: 04/01/2019

Document Version:

Accepted manuscript including changes made at the peer-review stage

Please check the document version of this publication:

- A submitted manuscript is the version of the article upon submission and before peer-review. There can be important differences between the submitted version and the official published version of record. People interested in the research are advised to contact the author for the final version of the publication, or visit the $\mathrm{DOI}$ to the publisher's website.

- The final author version and the galley proof are versions of the publication after peer review.

- The final published version features the final layout of the paper including the volume, issue and page numbers.

Link to publication

\section{General rights}

Copyright and moral rights for the publications made accessible in the public portal are retained by the authors and/or other copyright owners and it is a condition of accessing publications that users recognise and abide by the legal requirements associated with these rights.

- Users may download and print one copy of any publication from the public portal for the purpose of private study or research.

- You may not further distribute the material or use it for any profit-making activity or commercial gain

- You may freely distribute the URL identifying the publication in the public portal.

If the publication is distributed under the terms of Article $25 \mathrm{fa}$ of the Dutch Copyright Act, indicated by the "Taverne" license above, please follow below link for the End User Agreement:

www.tue.nl/taverne

Take down policy

If you believe that this document breaches copyright please contact us at:

openaccess@tue.nl

providing details and we will investigate your claim. 


\title{
On Free-Space Antenna Reflection Phase Measurements in a Reverberation Chamber
}

\author{
L.A. Bronckers, A. Roc'h and A.B Smolders \\ Department of Electrical Engineering \\ Eindhoven University of Technology \\ Eindhoven, The Netherlands
}

\begin{abstract}
A reverberation chamber is a very useful tool to obtain the radiation efficiency of an antenna. While it has been shown that the magnitude of the reflection coefficient can be obtained from these measurements as well, this has not yet been shown for the phase of the reflection coefficient. This would allow for a full characterization of the antenna's behavior as seen from its input port. In this paper it is shown that the phase of the freespace reflection coefficient can be obtained from measurements in a reverberation chamber by taking the angle of the ensemble average of the individual reflection coefficients. This has been empirically verified by comparing several sets of measurement data from the reverberation chamber to their anechoic chamber equivalents for several antennas.
\end{abstract}

\section{INTRODUCTION}

An important characteristic of measured S-parameters in a reverberation chamber (RC) is that the absolute value of the ensemble average should match the absolute value of a single measurement in an anechoic chamber (AC), if a sufficient amount of independent samples is taken in the RC [1], [2]. This allows one to obtain all required data for antenna efficiency measurements in the $\mathrm{RC}$, without requiring one to perform a separate test in an anechoic environment. This principle has been verified up to $6 \mathrm{GHz}$ [1]. For the design of a matching circuit for the antenna under test, it would be very useful to also obtain the phase of the reflection coefficient. However, to the best of the authors' knowledge, no comparison has yet been made with respect to the phase of the reflection coefficient. In this paper an expression to obtain the freespace reflection coefficient phase from reverberation chamber measurements is given and verified. In Section II the theory is discussed and the experiment is described, followed by the results and discussion in Section III and a conclusion in Section IV.

\section{THEORY AND EXPERIMENT}

In most applications, the antenna will radiate into freespace, which has an impedance derived from Maxwell's equations given by $\eta_{0}=\frac{E}{H} \approx 377 \Omega$. Therefore it is desirable to perform measurements under this condition. Meanwhile, for an ideal reverberation chamber, it has been shown that [2]:

$$
\eta_{0}^{2}=\frac{\left\langle\left|\vec{E}\left(\vec{r}_{1}\right)\right|^{2}\right\rangle}{\left\langle\left|\vec{H}\left(\vec{r}_{2}\right)\right|^{2}\right\rangle}
$$

where $\langle\cdot\rangle$ denotes the ensemble average, $\vec{E}$ and $\vec{H}$ are electric and magnetic field and $\vec{r}_{1}$ and $\vec{r}_{2}$ are arbitrary locations within the working volume. Equation 1 was also verified in the 200-500 MHz region using field probes [3]. As $\vec{r}_{1}$ and $\vec{r}_{2}$ are arbitrary locations, they can also to be the same. Thus, if the ensemble average is taken, the ratio of the electric and magnetic fields is equal to the free-space impedance in an ideal RC. Therefore, the antenna should, on average, 'see' the free-space impedance. Since the antenna can be assumed to be linear and reciprocal, this means that its reflection coefficient should converge towards the free-space reflection coefficient. Defining $S_{11, R C}$ as a single complex reflection coefficient obtained in the reverberation chamber, and $S_{11, A C}$ as a complex reflection coefficient obtained in an anechoic chamber, it has already been demonstrated that [1], [2]:

$$
\left|\left\langle S_{11, R C}\right\rangle\right|=\left|S_{11, A C}\right|,
$$

which confirms that at least the absolute value of the reflection coefficient in the RC converges towards the absolute value of the free-space reflection coefficient, allowing one to compensate for impedance mismatch in antenna efficiency measurements. From (1) and the reasoning above, the following should also hold:

$$
\phi\left(\left\langle S_{11, R C}\right\rangle\right)=\phi\left(S_{11, A C}\right),
$$

where $\phi(\cdot)$ signifies taking the phase. In words, that the phase of the ensemble average of the measured reflection coefficients in the $\mathrm{RC}$ converges towards the free-space reflection phase of the antenna. The equality introduced in (3) will be verified experimentally by comparing measurement results from the $\mathrm{RC}$ to those from the AC.

The antennas used for the experimental verification are three double-ridged horns, namely a Com-power AH-118, referred to as horn A [4]), an EMCO 3115, referred to as horn B [5]) and a Schwarzbeck BBHA-9120-D, referred to as horn C [6]). They are shown in Fig. 1a, 1b and 1c, respectively. All antennas have return loss higher than $7 \mathrm{~dB}$ across the 1-6 GHz band that is used, except for Horn A which peaks to $5.8 \mathrm{~dB}$ at $1.9 \mathrm{GHz}$.

The VNA is calibrated up to the antenna connectors for both measurements in $\mathrm{RC}$ and $\mathrm{AC}$. The antennas are positioned in the reverberation chamber at Eindhoven University of Technology. This is a $4.05 \times 5.7 \times 3.15 \mathrm{~m}^{3}$ room that uses a folding wall as stirring mechanism [7], as shown in Fig. 1d, with $N=100$ different positions in a linear fashion. The measurements are performed in tuning mode. In addition, 


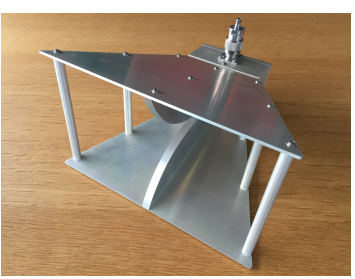

(a)

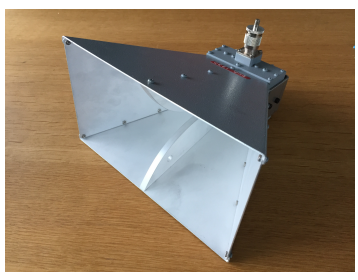

(c)

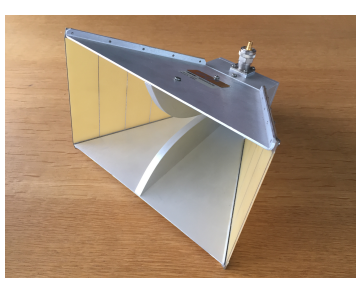

(b)

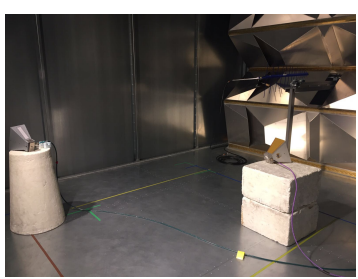

(d)
Fig. 1. Horn A (a), Horn B (b) and Horn C (c), including their SMA adaptors, and the setup in the RC (d).

frequency-stirring over a $100 \mathrm{MHz}$ bandwidth is performed. In the $\mathrm{AC}$ the horns are placed one at a time, facing at least $3 \mathrm{~m}$ of free space before encountering an absorber. Each of the antennas is measured twice in the RC and once in the AC.

\section{RESULTS AND DISCUSSION}

The results of the measurements are shown in Fig. 2 for all three horns. Each of the horns exhibits a distinct behavior, which is to be expected as they are only conceptually similar, being quite different in their execution. In the figures it can be seen that the curves for all measurements overlap; it is quite difficult to distinguish the dashed and dotted lines of the RC measurements from the solid lines of the $\mathrm{AC}$ measurements. Therefore, the phase differences between the measurements are shown in Fig. 3. In this figure it can be observed that, except for inaccuracy peaks for some of the measurements around $1.7 \mathrm{GHz}$ and $5.6 \mathrm{GHz}$, the differences remain below $5 \%$. As the phase accuracy of the open and short standards in the calibration kit used are guaranteed within $\pm 2.0 \mathrm{deg}$ [8] and some cables were moved between calibration and measurement, it seems likely that the differences are due to measurement inaccuracies.

\section{CONCLUSION}

In this paper it is shown that the phase of the free-space reflection coefficient can be obtained from measurements in a reverberation chamber. This can be done by taking the angle of the ensemble average of the indidivual reflection coefficients, which has been empirically verified by comparing several sets of measurement data from the reverberation chamber to their anechoic chamber equivalents for several antennas. The difference between the measurements is found to be sufficiently small to conclude that the phase of the free-space reflection coefficient can indeed be derived from reverberation chamber measurements. This means that the antenna's behavior at its input port can be fully characterized

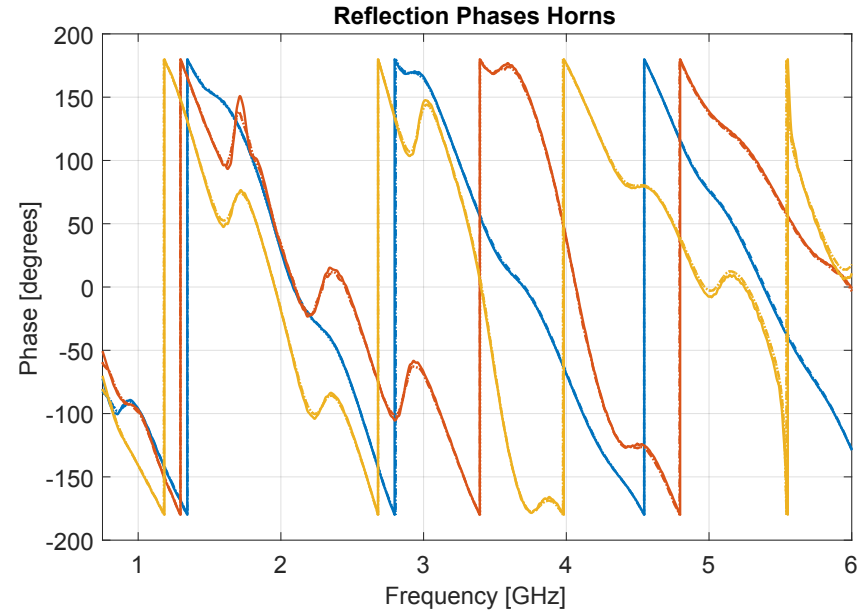

Fig. 2. Measured phases of input reflection of Horn A (blue), B (red) and C (yellow). Results from the anechoic chamber are shown in solid lines, while the measurements from the reverberation chamber are shown in dotted and dashed lines.

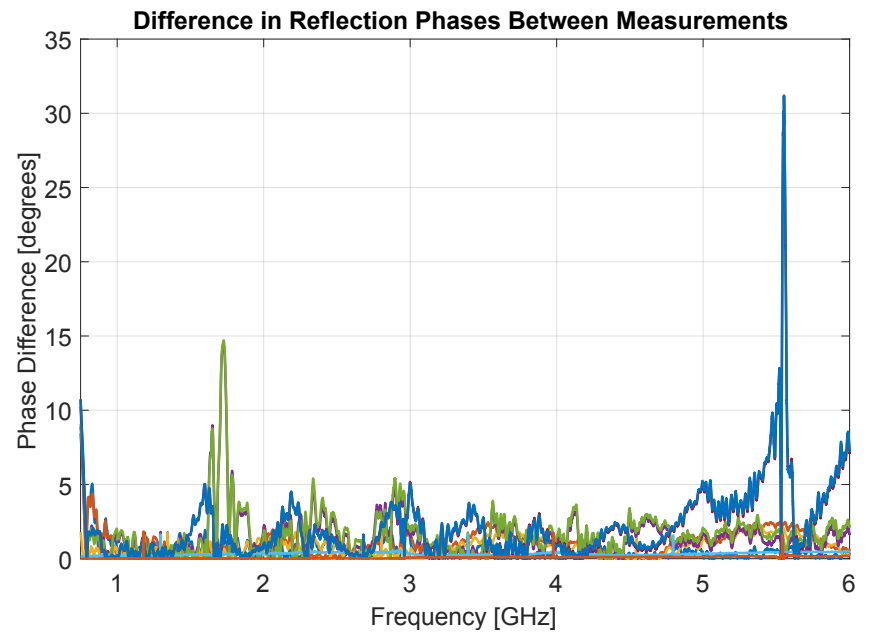

Fig. 3. Differences between all measured phases.

in a reverberation chamber, allowing for instance the design of a matching network.

\section{REFERENCES}

[1] C. L. Holloway, H. A. Shah, R. J. Pirkl, W. F. Young, D. A. Hill, and J. Ladbury, "Reverberation Chamber Techniques for Determining the Radiation and Total Efficiency of Antennas," IEEE Trans. Antennas Propag., vol. 60, no. 4, pp. 1758-1770, apr 2012.

[2] D. A. Hill, Electromagnetic Fields in Cavities. Hoboken, NJ, USA: John Wiley \& Sons, Inc., sep 2009, vol. 43, no. 08.

[3] G. H. Koepke and M. L. Crawford, "Design, evaluation, and use of a reverberation chamber for performing electromagnetic susceptibility/vulnerability measurements," 1986.

[4] Com-Power Corporation, "Double Ridge Horn AH-118 Datasheet."

[5] ETS-Lindgren, "Double-Ridged Waveguide Horn Antennas Datasheet."

[6] Schwarzbeck Mess-Elektronik, "BBHA-9120-D Datasheet."

[7] R. Serra, A. C. Marvin, F. Moglie, V. M. Primiani, A. Cozza, L. R. Arnaut, Y. Huang, M. O. Hatfield, M. Klingler, and F. Leferink, "Reverberation chambers a la carte: An overview of the different mode-stirring techniques," IEEE Electromagn. Compat. Mag., vol. 6, no. 1, pp. 63-78, 2017.

[8] Maury Microwave Corporation, "TC-CK-35 3.5mm Instrument-Grade VNA Calibration Kit,” p. 91764, 2010. 